\title{
ORGANIZATION OF THE ONLINE LABORATORY PRACTICUM AT INORGANIC AND ANALYTICAL CHEMISTRY - A POSSIBLE SOLUTION FOR PANDEMIC SITUATION
}

\author{
lurie Subotin ${ }^{1^{*}}$, ORCID ID : 0000-0002-5570-4713, \\ Raisa Druţă ${ }^{1}$, ORCID ID : 0000-0001-5301-6055, \\ Zinaida Chiosa ${ }^{2}$ \\ ${ }^{1}$ Technical University of Moldova, Stefan cel Mare 168, Chisinau, Republic of Moldova \\ 2Liceum "Da Vinci", Constantin Stamati, 10, Chisinau, Republic of Moldova \\ ${ }^{*}$ Corresponding author: lurie Subotin, iurie.subotin@ftmia.utm.md
}

Received: 04. 17. 2021

Accepted: 05. 18. 2021

\begin{abstract}
The article analyzes the possible methods for performing laboratory work in chemistry during a situation of lockdown or pandemic. Laboratory practice is one of the main ways to learn the basics of science. The results of the experiments performed by the students stimulate their thinking, lead them to discussions and lead them to draw conclusions. All this leads to the optimization of the learning process. The use of very simple tools often helps in learning, facilitating the assimilation of the material. If the transfer of knowledge is not done correctly initially, then the subsequent understanding of the material will be more difficult to achieve. In the absence of a strong connection with previously studied topics it will be more difficult for students to think. Students begin to believe that science is difficult to understand, interest is often lost, and knowledge gained during the theoretical course may lose its value. People are naturally curious and always on the lookout, and the lab is a good place to satisfy that curiosity. In the laboratory, students have the opportunity to test their theoretical knowledge, which structures thinking and increases interest in science.
\end{abstract}

Keywords: education, chemical experiment, inorganic chemistry, virtual laboratory, video sequence.

Rezumat. În articol sunt analizate metodele posibile pentru efectuarea lucrărilor de laborator la chimie în timpul unei situații de blocare sau pandemie. Practica de laborator este una dintre principalele modalități de a învăța elementele de bază ale științelor. Rezultatele experimentelor realizate de elevi le stimulează gândirea, conduc la discuții și îi determină să facă concluzii. Toate acestea conduc la optimizarea procesului de învățare. Utilizarea instrumentelor foarte simple ajută adesea la învățare, facilitând asimilarea materialului. Dacă transferul de cunoștințe nu se face corect inițial, atunci înțelegerea ulterioară a materialului va fi mai dificil de realizat. În absența unei legături puternice cu subiectele studiate anterior va fi mai dificil pentru studenți să gândească. Elevii încep să 
creadă că știința este greu de înțeles, deseori interesul este pierdut, iar cunoștințele acumulate în timpul cursului teoretic și-ar putea pierde valoarea. Oamenii sunt curioși în mod natural și sunt mereu în căutare, iar laboratorul este un loc bun pentru a satisface această curiozitate. În laborator studenții au posibilitatea de a-și testa cunoștințele teoretice, care structurează gândirea și crește interesul pentru știință.

Cuvinte cheie: educație, experiment chimic, chimia anorganică, laborator virtual, secvență video.

\section{Introducere}

Procesul instructiv-educativ la disciplina chimie este orientat spre formarea la studenţi a unui şir de competenţe specifice, precum: a dobândi cunoştinţe fundamentale, abilităţi şi valori din domeniul chimiei; a investiga experimental substanţele şi procesele chimice; a utiliza inofensiv substanţele chimice; a rezolva probleme/situaţii-problemă.

Experimentul chimic este o componentă indispensabilă în predarea chimiei şi reprezintă o metodă extrem de importantă în stabilirea unei legături temeinice dintre teorie şi practică, transformând astfel cunoştinţele obţinute în convingeri şi abilităţi cognitive. În programa liceală şi în programa universitară un rol esenţial este rezervat experimentului chimic, în procesul realizării căruia elevii şi studenţii obţin nişte aptitudini de a observa, analiza, propune concluzii, de mânuire cu utilajul şi reagenţii chimici.

Experimentul chimic permite familiarizarea nu numai cu fenomenele cercetate, dar şi cu metodele ştiinţifice ale chimiei; sporeşte atractivitatea disciplinei; formează nişte deprinderi şi aptitudini practice. În procesul realizării experienţelor studenţii însuşesc mai temeinic şi profund conţinuturile disciplinei, obţinând deprinderi de lucru sine stătător. Realizând experimentul şi notând rezultatele transformărilor chimice observate, studentul se încredinţează că procesele chimice pot fi dirijate şi se supun unor legităţi, cunoaşterea cărora conduce la confirmarea teoriei în practică, o aplicabilitate clară în activitatea practică.

Metodele de învăţare a chimiei în procesul de instruire sunt integrate, din care cauză se analizează utilizarea eficientă a corelării diferitor metode, care sunt determinate de obiectivul didactic, conţinutul temei, particularităţile de vârstă, nivelul de pregătire a grupei şi alţi factori $[1,2]$. Un factor determinant în formarea competenţelor specifice la chimie este transformarea cunoştinţelor teoretice în convingeri praxiologice stabile. Prin experienţele demonstrative de laborator şi lucrările practice, organizate atât în cadrul cursurilor, cât şi a activităţilor extra-didactice se creează condiţiile necesare pentru formarea la studenţi a competenţei de investigare teoretică şi experimentală [3]. Investigarea experimentală a proprietăţilor şi obţinerii substanţelor chimice, studierea acţiunii unor procese chimice asupra omului şi mediului relevă necesitatea de a asigura securitatea personală şi socială şi de a promova modul sănătos de viaţă. Ca urmare efectuarea experienţelor de laborator şi a lucrărilor practice conform instrucţiunilor propuse şi respectarea regulilor de securitate asigură suportul pentru utilizarea inofensivă a substanţelor în diverse situaţii cotidiene.

\section{Rezultate şi discuţii}

Organizarea activităţilor educaţionale în formatul online cu aplicarea tehnologiilor informaţ̧ionale pentru ultima perioadă nu prezintă o noutate şi deja este un mijloc obişnuit de organizare a procesului instructiv-educativ, în special în perioada pandemiei Covid-19 [4]. Însă dacă organizarea şi realizarea orelor de curs şi seminare nu prezintă dificultăți 
majore, atunci efectuarea lucrărilor de laborator de studenţi în varianta online cauzează un şir de întrebări la modul de realizare, eficienţa activităţii, crearea deprinderilor practice, etc.

În opinia autorilor, evident, efectuarea online a lucrărilor de laborator la disciplina chimie nu este o soluţie echivalentă cu prezenţa fizică a studenţilor în laborator. Efectuarea online a lucrărilor de laborator este posibilă pe 2 căi:

$\checkmark$ aplicarea laboratoarelor virtuale [5]

$\checkmark$ utilizarea secvenţelor video ale experienţelor corespunzătoare.

Prin intermediul experimentelor virtuale este posibil de a descrie orice situaţii din viaţa reală, indiferent de gradul de complexitate şi de pericol al acestora. Deoarece sunt simulate pe calculator, procesele pot fi repetate până când sunt înţelese pe deplin. Resursele digitale cuprinse de laboratoarele virtuale sunt atractive şi uşor de utilizat de studenţi transformând astfel activitatea practică într-o activitate unică şi plăcută. În domeniul analizat pot fi evidenţiate un şir de portaluri ce permit realizarea experimentului chimic virtual, fie în limba engleză, română, rusă [6 - 11].

Avantajele unui experiment chimic virtual sunt: siguranța, posibilitatea unei activităţi individuale; perspective ale educației chimice incluzive; posibilitatea efectuării unui experiment în absența fizică a echipamentelor complexe, reactivi inaccesibili, capacitatea de a efectua rapid o serie de experimente cu valori diferite ale parametrilor de intrare; reducerea timpului pentru exersarea abilităților, dobândirea abilității de observare, interpretare a datelor; în același timp, există situații în care utilizarea unui laborator virtual este singura modalitate posibilă efectuarea unui experiment chimic.

Desigur, există unele dezavantaje ale experimentului chimic virtual. Principala este lipsa contactului direct cu instrumentele și echipamentele și, cel mai important, cu obiectul cercetării chimice - o substanță cu un set complex de caracteristici și proprietăți pe care nimeni nu le poate reproduce cel mai perfect model de computer. Evident, combinația optimă va fi utilizarea laboratoarelor naturale și virtuale în procesul educațional, luând în considerare avantajele și dezavantajele lor inerente.
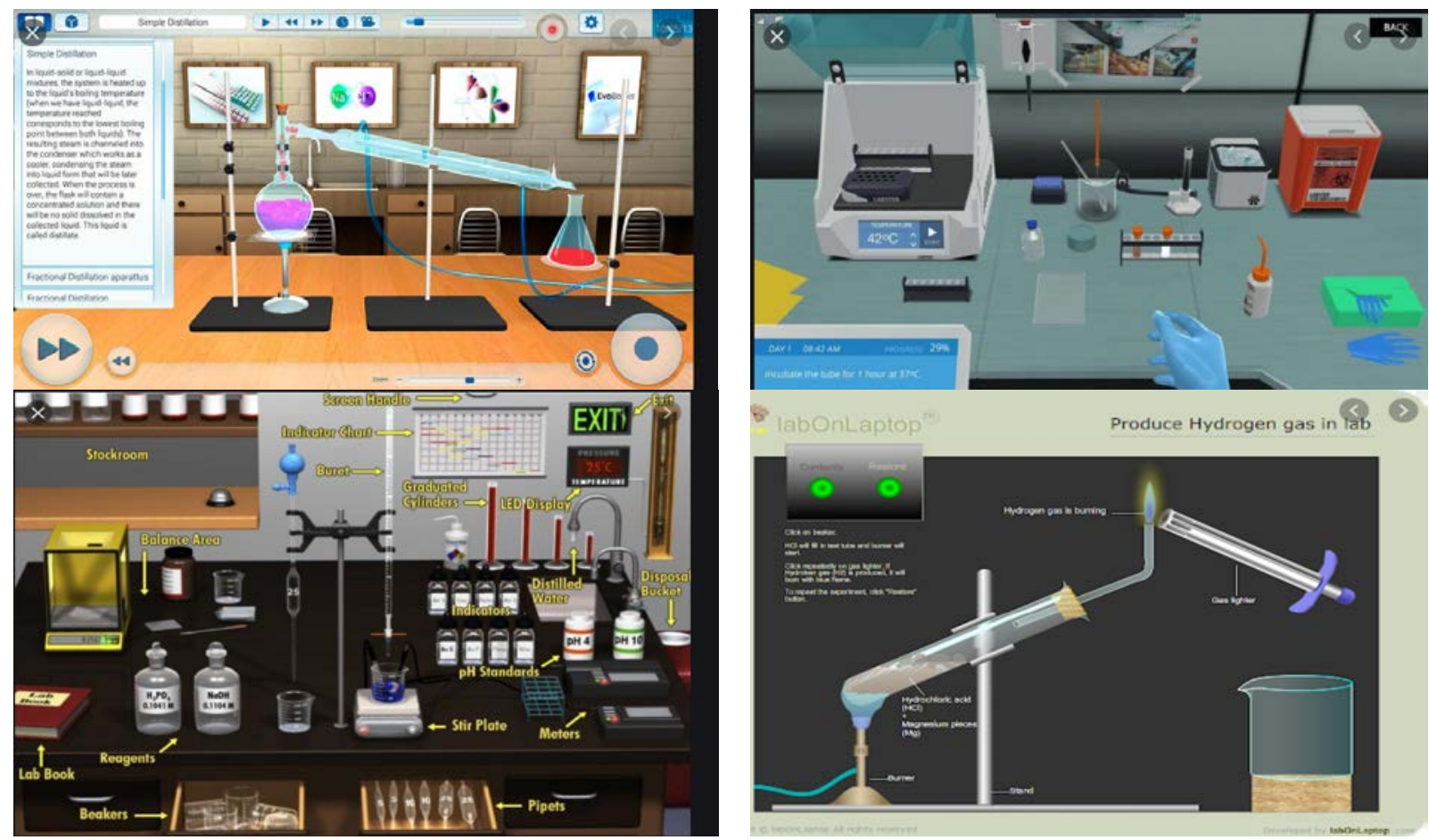

Figura 1. Mostre de ustensile şi reagenţi propuse de laboratorul virtual. 
Unul din neajunsuri constă în lipsa vizualizării reale a rezultatelor experimentale (culoarea soluţiei, precipitatului, gazului eliminat, formarea precipitatului, etc).

O altă posibilitate de efectuare online a lucrărilor de laborator constă fie în utilizarea secvențelor video deja filmate (youtube.com), fie filmarea lor de cadrele didactice. Drept exemplu se propune modalitatea de realizare a lucrării de laborator la chimia anorganică „Reacţii de schimb ionic”, care se efectuează de studenţii de la toate specialităţile UTM.

Lucrarea practică este formată din 9 experiențe:

1. Obţinerea sărurilor insolubile
a. Obţinerea iodurii de plumb (II)
b. Obţinerea sulfatului de bariu
c. Obţinerea sulfurii de cupru (II)

2. Obţinerea unui acid insolubil

3. Obţinerea unui produs de reacţie gazos

a. Obţinerea oxidului de carbon (IV)

b. Obţinerea amoniacului

4. Obţinerea bazelor insolubile

a. Obţinerea hidroxidului de fier (III)

b. Obţinerea hidroxidului de cupru (II)

c. Obţinerea hidroxidului de aluminiu

Pentru realizarea eficientă a lucrării studenţilor se oferă (pe email) descrierea lucrării de laborator, întrebări pentru pregătire sinestătătoare, template-ul lucrării. Template-ul conţine denumirea lucrării; scopul lucrării, utilaje, ustensile şi reagenţii utilizaţi, grupa, numele studentului necesită a fi completate de student.

\begin{tabular}{|c|c|}
\hline Octombrie, 2020 & DEPARTAMENTUL OENOLOGIE ŞI CHIMIE \\
\hline Disciplina CHIMIA ANORGANICĂ & Numele, prenumele studentului \\
\hline \multirow[t]{3}{*}{ Grupa } & Verificat profesor \\
\hline & rare practică \\
\hline & acții de schimb ionic" \\
\hline \multicolumn{2}{|l|}{$\begin{array}{l}\text { Scopul: } \\
\text { Utilaje si reactivi: }\end{array}$} \\
\hline & Efectuarea lucrării \\
\hline
\end{tabular}

Figura 2. Aspectul lucrării de laborator.

Ulterior studentul face cunoştinţă cu modul de efectuare a fiecărei experienţe, observă spaţiile libere necesare pentru plasarea imaginilor din secvenţa video vizionată, observaţii, concuzii:

La dispoziţia studenţilor se pune un set de secvenţe video. Studenţii privesc secvenţa video ce corespunde experienţei [12], selectează imaginile necesare pentru plasare în tabelul respectiv (figura 3 ), atent privesc rezultatele experimentului şi notează observaţiile şi concluziile. Rezultatele obţinute pot avea forma: 
Experienţa 1. Obținerea sărurilor insolubile

a. Obținerea iodurii de plumb (II)

Vizionați secvența video $\mathrm{nr} .1$.

Turnați într-o eprubetă 1-2 ml soluţie nitrat de plumb (II) şi 1-2 ml soluție iodură de potasiu. Observați ce se întâmplă. Notați ecuația reacției în formă moleculară şi ionică:

EM

EIC

EIR

\begin{tabular}{|l|l|}
\hline Imaginea până la reacţie & Imaginea după reacţie \\
\hline & \\
& \\
& \\
\hline
\end{tabular}

Observație

Concluzie

Figura 3. Aspectul necompletat a experienţei nr. 1 a.

Experiența 1. Obținerea sărurilor insolubile

a. Obținerea iodurii de plumb (II)

Vizionați secvența video $\mathrm{nr} .1$.

Turnați într-o eprubetă 1-2 ml soluţie nitrat de plumb (II) şi 1-2 ml soluție iodură de potasiu. Observați ce se întâmplă. Notați ecuația reacției în formă moleculară şi ionică:

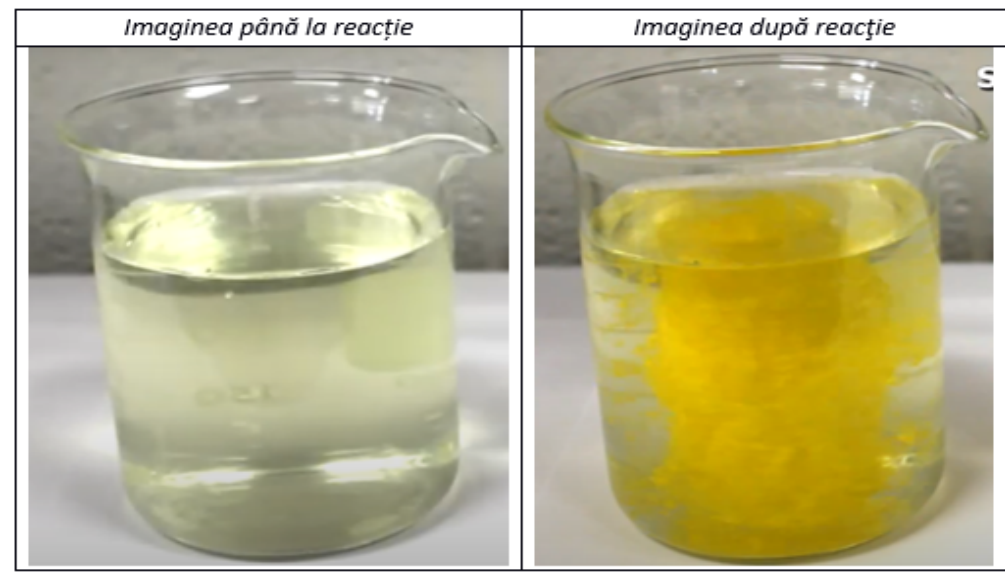

Ecuația reacției:

$\begin{array}{ll}\mathrm{Pb}\left(\mathrm{NO}_{3}\right)_{2}+2 \mathrm{KI} \rightarrow \mathrm{Pbl}_{2} \downarrow+2 \mathrm{KNO}_{3} & \text { EM } \\ \mathrm{Pb}^{2+}+2 \mathrm{NO}_{3}{ }^{-}+2 \mathrm{~K}^{+}+2 \mathrm{I}^{-} \rightarrow \mathrm{Pbl}_{2} \downarrow+2 \mathrm{~K}^{+}+2 \mathrm{NO}_{3}^{-} & \text {EIC } \\ \mathrm{Pb}^{2+}+2 \mathrm{I}^{-} \rightarrow \mathrm{Pbl}_{2} \downarrow & \text { EIR }\end{array}$

Observație: în rezultatul reacției s-a format un precipitat de culoare galbenă.

Concluzie: Reacția a decurs între ionul $\mathrm{Pb}^{2+}$ și $\mathrm{I}^{-}$.

Figura 3. Aspectul completat a experienţei nr. 1a.

Analog, se procedează şi în experienţa 1 b - „Obţinerea sulfatului de bariu”. Studenţii accesează secvenţa video indicată de profesor în instrucţiune [13] şi efectuează toate etapele propuse anterior. 
b. Obținerea sulfatului de bariu

Turnați într-o eprubetă 1-2 ml soluție clorură de bariu și 1-2 ml soluție sulfat de sodiu. Notați ecuația reacției în formă moleculară și ionică:

\begin{tabular}{|l|l|l|}
\hline Imaginea până la reacție & & Imaginea după reacție \\
\hline & & \\
\hline
\end{tabular}

$$
\begin{array}{ll}
\mathrm{BaCl}_{2}+\mathrm{Na}_{2} \mathrm{SO}_{4} \rightarrow \mathrm{BaSO}_{4} \downarrow+2 \mathrm{NaCl} & \text { EM } \\
\mathrm{Ba}^{2+}+2 \mathrm{Cl}^{-}+2 \mathrm{Na}^{+}+\mathrm{SO}_{4}^{2-} \rightarrow \mathrm{BaSO}_{4} \downarrow+2 \mathrm{Na}^{+}+2 \mathrm{Cl}^{-} & \text {EIC } \\
\mathrm{Ba}^{2+}+\mathrm{SO}_{4}^{2-} \rightarrow \mathrm{BaSO}_{4} \downarrow & \text { EIR }
\end{array}
$$

Observație: În rezultatul reacției s-a format un precipitat de culoare albă.

Concluzie: Reacția a decurs între ionul $\mathrm{Ba}^{2+} \mathrm{ș}_{\mathrm{SO}_{4}}{ }^{2-}$.

Figura 4. Aspectul completat a experienţei nr. 1b.

În experienţa 1c se demonstrează formarea unei sulfuri insolubile [14]. Toate etapele din experienţă sunt identice cu cele anterioare:

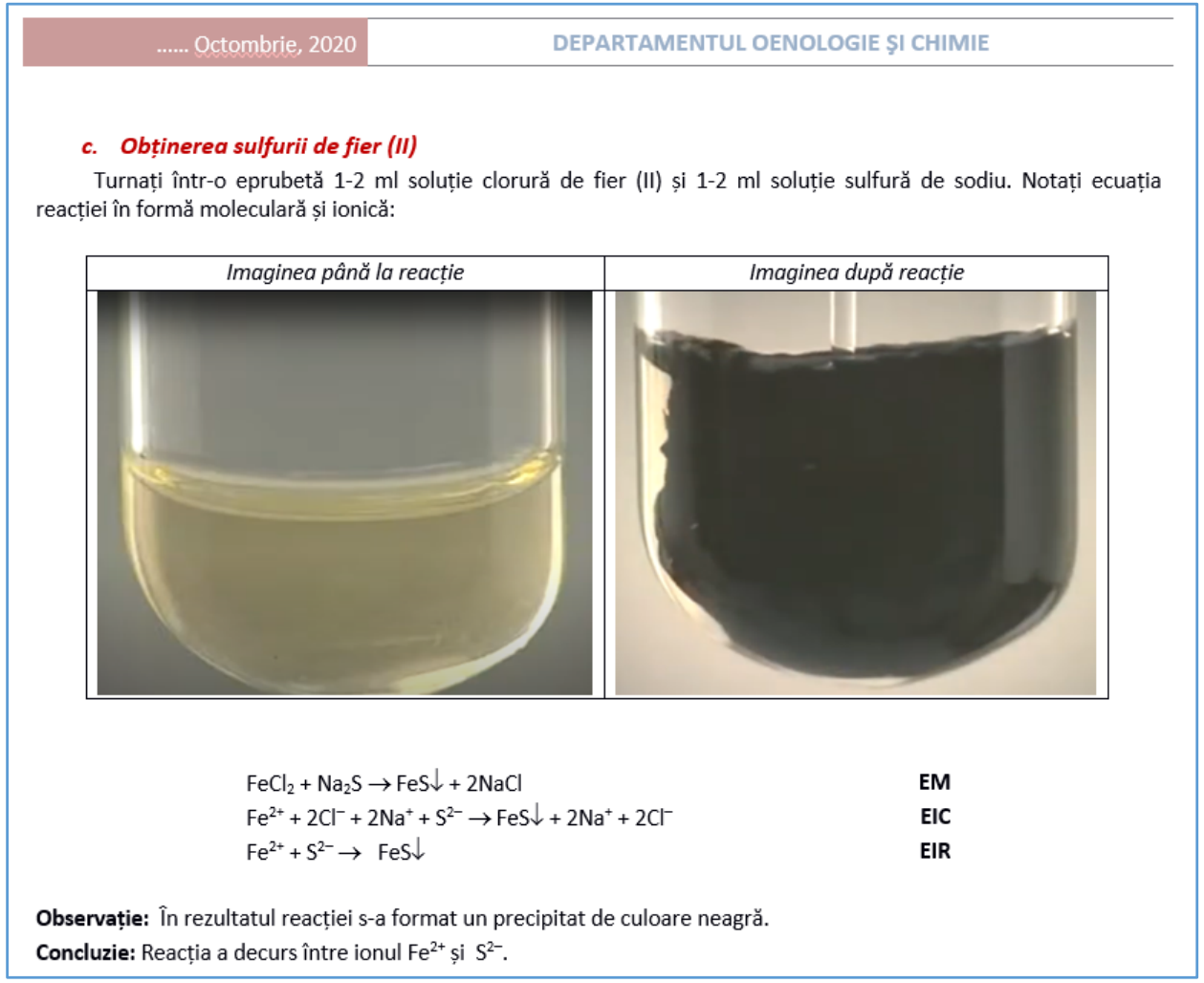

Figura 4. Aspectul completat a experienţei nr. 1c. 
-..... Sentembrie, 2020

Disciplina CHIMIA ANALITICĂ

Grupa TPA-201
DEPARTAMENTUL OENOLOGIE ŞI CHIMIE

Numele, prenumele studentului

Verificat profesor

\section{Lucrare practică \\ Tema „Determinarea concentrației de acizi prin metoda de titrare”}

Scopul: Determinarea concentrației soluției $\mathrm{HCl}$ prin metoda de titrare

Utilaje şi reactivi: Baloane cotate, pahare chimice, biuretă pentru titrare, soluţie titrată $\mathrm{NaOH}$, fenolftaleină, apă distilată

\section{Modul de efectuare}

Proba primită de la profesor o cu un conținut necunoscut de acid $\left(\mathrm{HCl}, \mathrm{H}_{2} \mathrm{SO}_{4}, \mathrm{CH} 3 \mathrm{COOH}\right)$ am transferat cantitativ soluția obținută cu ajutorul unei pâlnii într-un balon cotat de $100 \mathrm{ml}$ și am adus până la cotă cu apă distilată. Cu ajutorul unei pipete am transferat într-un balon cotat pentru titrare $10 \mathrm{ml}$ de acid, am adăugat 2-3 picături de indicator (tipul indicatorului se selectează în funcție de acidul titrat).

Am umplut biureta pentru titrare cu solutia de lucru de $\mathrm{NaOH}$ sau $\mathrm{KOH}$ și am titrat soluția de acid până la apariția unei colorații slabe, dar stabile timp de $30 \mathrm{sec}$. Titrarea am executat cel puțin de 3 ori până la obținerea unor rezultate ce variază nu mai mult de $0,1 \mathrm{ml}$.

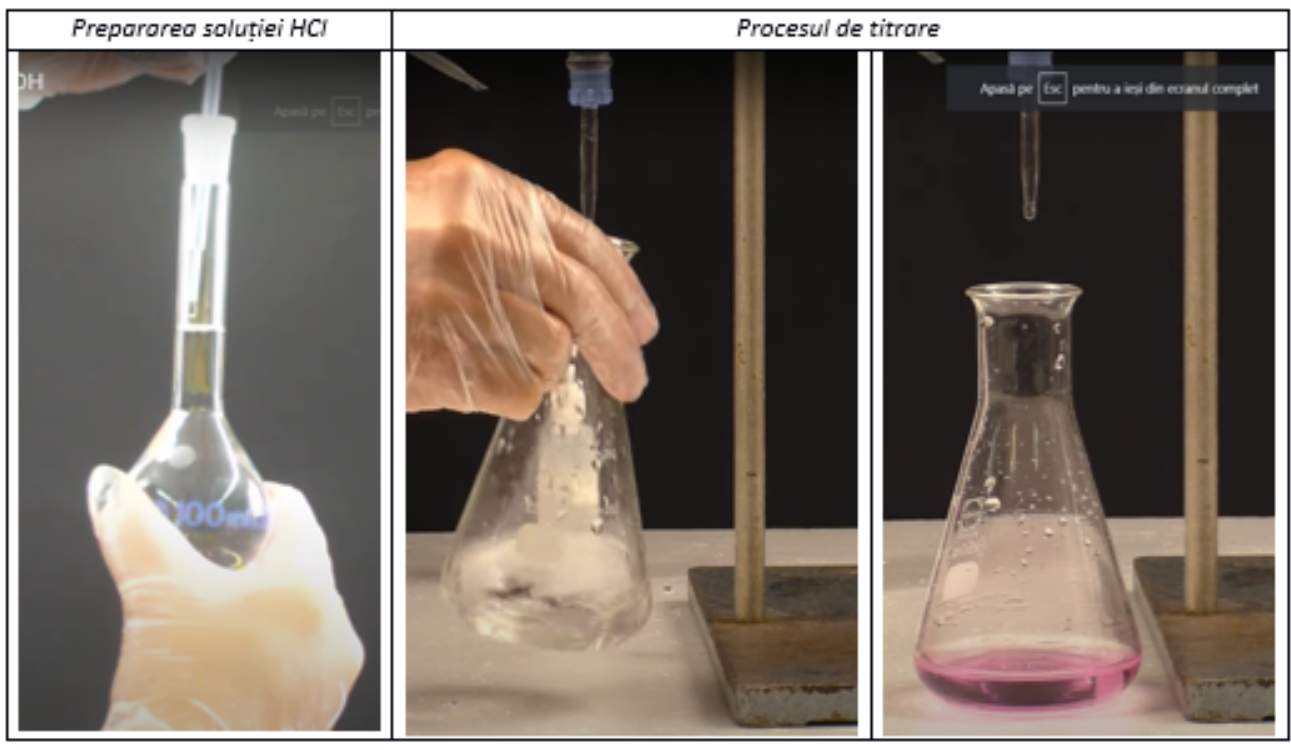

Calculul continutului de acid

Volumul $\mathrm{KOH}$ obtinut la titrare:

\begin{tabular}{|l|l|l|}
\hline$V_{1}=4,7 \mathrm{ml}$ & & $C_{N}(\mathrm{KOH})=1,0125 \mathrm{~mol} / 1$ \\
$V_{2}=4,7 \mathrm{ml}$ & & \\
$V_{3}=4,8 \mathrm{ml}$ & $V_{m e d}=4,73 \mathrm{ml}$ & \\
\hline
\end{tabular}

Titrul soluției| KOH:

$$
\begin{aligned}
& T_{\left(\frac{\mathrm{KOH}}{\mathrm{HCl}}\right)}=\frac{C_{n}(\mathrm{HCl}) \cdot \mathrm{ME}(\mathrm{HCl})}{1000}=\frac{1,0125 \cdot 36,5}{1000}=0,0369 \mathrm{~g} / \mathrm{cm}^{3} \\
& m(H C l)=T\left(\frac{K O H}{H C l}\right) \cdot V_{m e d .(K O H)} \cdot \frac{100}{10}=0,0369 \cdot 4,73 \cdot \frac{100}{10}=1,7453 g
\end{aligned}
$$

Concluzie: În rezultatul efectuării lucrării de laborator am făcut cunoștință cu metoda de titrate acido-bazică şi am determinat masa acidului clorhidric în proba propusă.

Figura 5. Aspectul completat al lucrării de laborator „Determinarea concentrației de acizi prin metoda de titrare". 
Analog se efectuează şi restul experienţelor. Pentru aceasta studenţii utilizează linkurile indicate $[15,16,17,18,19,20]$.

În final, studentul completează varianta electronica a lucrării de laborator şi o transmite pe email profesorului. Profesorul verifică corectitudinea lucrării şi în discuţia online cu studentul asupra lucrării stabilește nota.

Analog pot fi realizate şi alte lucrări de laborator atât la disciplina Chimia anorganică, atât şi alte discipline: Chimia analitică, Chimia organică, Chimia fizică.

Un alt exemplu - lucrarea de laborator la disciplina Chimia analitică „Determinarea concentraţiei de acizi prin metoda de titrare". Analog, ce propune template-ul lucrării, studenţii vizionează secvenţa video $[21,22]$ şi prezintă lucrarea profesorului.

\section{Concluzii}

În rezultatul analizei bibliografiei și propriilor cercetări considerăm că executarea lucrărilor de laborator în varianta online este posibilă prin aplicarea metodelor digitale moderne. Executarea lucrărilor poate fi realizată atât prin aplicarea laboratoarelor virtuale, cât și prin vizionarea și analiza atentă a secvențelor video corespunzătoare. Evident, modalitatea online de efectuare a lucrărilor de laborator la chimie nu poate înlocui executarea fizică a acestora, însă în condițiile pandemiei și absenţei studenţilor la ore modalitatea poate utilizată fie pentru studenții tuturor profilurilor, fie pentru studenţii la care disciplina chimia nu este de profil.

\section{References}

1. Fatu S. Didactica chimiei, Bucuresti, 2007.

2. Cozma D. G., Pui A. Elemente de didactica chimiei, lasi, Ed. Spiru Haret, 2003.

3. Subotin C., Revenco M., Subotin lu. Experimentul demonstrativ-distractiv la chimie. Chişinău, Ed. Lumina. 2003.

4. Arroio A. The value of education in the context of Covid-19 pandemic / A. Arroio // Problems of Education in the 21st Century. - 2020. - V. 78(3). - P. 309-313.

5. Subotin lu., Druţă R. Chemical experiment and its importance in teaching chemistry. Journal of Social Sciences, Vol. II, no. 1 (2019), pp. 21-26.

\section{Surse online:}

6. Virtual Chemistry Laboratory Merlot II: https://www.merlot.org/merlot/viewMaterial.htm?id=89055 [accesat 14.04.2021]

7. Virtual Chemistry: http://www.chem.ox.ac.uk/vrchemistry/) [accesat 14.04.2021]

8. Virtual Labs: http://www.vlab.co.in) [accesat 14.04.2021].

9. http://mmlab.ru/products/chemlab/chemlab.shtml. [accesat 14.04.2021]

10. VirtualLab (http://www.virtulab.net) [accesat 14.04.2021]

11. http://chemcollective.org/vlabs [accesat 14.04.2021]

12. https://www.youtube.com/watch?v=diW7q7RFJBM\&t=44s [accesat 14.04.2021]

13. https://www.youtube.com/watch?v=ymBbvSpT5RQ [accesat 14.04.2021]

14. https://www.youtube.com/watch?v=4ph78d_Xpol [accesat 14.04.2021]

15. https://www.youtube.com/watch? $v=3$ MnKt2X05Pc [accesat 14.04.2021]

16. https://www.youtube.com/watch?v=_D3Ctx-kwwY [accesat 14.04.2021]

17. https://www.youtube.com/watch?v=LUEakMDNRsM [accesat 14.04.2021]

18. https://www.youtube.com/watch?v=u4gmsggY5d8 [accesat 14.04.2021]

19. https://www.youtube.com/watch?v=FlvinJKn9Tg [accesat 14.04.2021]

20. https://www.youtube.com/watch?v=XSfuKRJpULY [accesat 14.04.2021]

21. https://www.youtube.com/watch?v=gSauVhYtVIU\& $\mathrm{t}=73 \mathrm{~s}$ [accesat 14.04.2021]

22. https://www.youtube.com/watch?v=QGAPGUbarAM [accesat 14.04.2021] 